\title{
Feasibility of basic transesophageal echocardiography in hemorrhagic shock: potential applications during resuscitative endovascular balloon occlusion of the aorta (REBOA)
}

\author{
William A. Teeter ${ }^{1}$, Bianca M. Conti ${ }^{2}$, Phil J. Wasicek ${ }^{3}$, Jonathan J. Morrison ${ }^{4}$, Dawn Parsell ${ }^{3}$, Bryan Gamble ${ }^{5}$,
} Melanie R. Hoehn ${ }^{6}$, Thomas M. Scalea ${ }^{7}$ and Samuel M. Galvagno Jr $r^{8^{*}}$

\begin{abstract}
Background: There are numerous studies in the cardiovascular literature that have employed transesophageal echocardiography (TEE) in swine models, but data regarding the use of basic TEE in swine models is limited. The primary aim of this study is to describe an echocardiographic method that can be used with relative ease to qualitatively assess cardiovascular function in a porcine hemorrhagic shock model using resuscitative endovascular balloon occlusion of the aorta (REBOA).

Methods: Multiplane basic TEE exams were performed in 15 during an experimental hemorrhage model using REBOA. Cardiac anatomical structure and functional measurements were obtained. In a convenience sample (two animals from each group), advanced functional cardiovascular measurements were obtained before and after REBOA inflation for comparison with qualitative assessments.

Results: Basic TEE exams were performed in 15 swine. Appropriate REBOA placement was confirmed using TEE in all animals and verified with fluoroscopy. Left ventricular volume was decreased in all animals, and left ventricular systolic function increased following REBOA inflation. Right ventricular systolic function and volume remained normal prior to and after hemorrhage and REBOA use. Mean ejection fraction (EF) decreased from 64\% (S.D. 9.6) to 62.1 (S.D. 16.8) after hemorrhage and REBOA inflation $(p=0.76)$; fractional area of change (FAC) decreased from 49.8 (S.D. 9.0) to 48.5 (S.D. 13.6) after hemorrhage and REBOA inflation ( $p=0.82$ ).
\end{abstract}

Conclusion: Basic TEE, which requires less training than advanced TEE, may be employed by laboratory investigators and practitioners across a wide spectrum of experimental and clinical settings.

\section{Background}

The porcine model is commonly used in cardiovascular research related to experimental models of hemorrhagic shock $[1,2]$. Swine are mammalian vertebrates with a cardiovascular system that is very similar to humans, and for this reason, have served as the dominant animal model for previous study designs published in the literature $[3,4]$.

\footnotetext{
* Correspondence: sgalvagno@som.umaryland.edu

${ }^{8}$ Department of Anesthesiology, Divisions of Critical Care Medicine and

Trauma Anesthesiology, University of Maryland School of Medicine,

Baltimore, MD, USA

Full list of author information is available at the end of the article
}

For instance, with regard to vascular size, an $80-100 \mathrm{~kg}$ swine has an aortic diameter of $1.6-1.8 \mathrm{~cm}$ versus an aortic diameter of $1.6-2.4 \mathrm{~cm}$ in a similarly-sized human $[1,5]$. However, several potentially significant differences exist. For example, porcine hearts are shaped more like a "valentine," have different orientations for insertion of the superior and inferior vena cava, and have dissimilar atrial components [5]. Table 1 summarizes some anatomical differences between swine and humans.

Transesophageal echocardiography (TEE) is an invasive diagnostic modality that carries minimal risk but requires

(c) The Author(s). 2018 Open Access This article is distributed under the terms of the Creative Commons Attribution 4.0 International License (http://creativecommons.org/licenses/by/4.0/), which permits unrestricted use, distribution, and reproduction in any medium, provided you give appropriate credit to the original author(s) and the source, provide a link to the Creative Commons license, and indicate if changes were made. The Creative Commons Public Domain Dedication waiver (http://creativecommons.org/publicdomain/zero/1.0/) applies to the data made available in this article, unless otherwise stated. 
Table 1 Major anatomical differences between porcine and human hearts

\begin{tabular}{|c|c|c|}
\hline Features & Porcine Heart & Human Heart \\
\hline Shape and Orientation & $\begin{array}{l}\text { "Valentine shaped heart" which is oriented in line } \\
\text { with the unguligrade stance of the pig }\end{array}$ & $\begin{array}{l}\text { "Trapezoidal" shaped heart oriented in line with the } \\
\text { orthograde posture of the human being }\end{array}$ \\
\hline Presence of tubular appendage & Observed in the right atrium & Observed in the left atrium \\
\hline Vena cava orientation & $\begin{array}{l}\text { The superior and inferior vena cava opens into the } \\
\text { right atrium at right angles to each other }\end{array}$ & $\begin{array}{l}\text { The superior and inferior vena cava open into the right } \\
\text { atrium in a straight line at } 180 \text { degrees }\end{array}$ \\
\hline Pulmonary veins & Left atrium receives 2 pulmonary veins & Left atrium receives 4 pulmonary veins \\
\hline Muscular moderator in right ventricle & $\begin{array}{l}\text { Prominent and situated more superior in the right } \\
\text { ventricle }\end{array}$ & $\begin{array}{l}\text { Less prominent and situated more inferior in the right } \\
\text { ventricle }\end{array}$ \\
\hline Characteristic of Apical components & Contains coarse and broad trabeculations & Trabeculations are absent and apex is narrower \\
\hline Aortic-Mitral fibrous continuity & $\begin{array}{l}\text { Reduced as } 2 / 3 R D \text { of aortic valve is supported } \\
\text { by left ventricular musculature }\end{array}$ & Not reduced \\
\hline Coronary Dominance & Left anterior descending coronary artery dominant & Right coronary dominant \\
\hline $\begin{array}{l}\text { Difference in right and left } \\
\text { atrio-ventricular branches }\end{array}$ & $\begin{array}{l}\text { Right atrio-ventricular branches are less developed } \\
\text { than left-sided equivalents }\end{array}$ & $\begin{array}{l}\text { No major differences exist between the right and left } \\
\text { atrio-ventricular branches }\end{array}$ \\
\hline
\end{tabular}

extensive knowledge about anatomy, physiology, and physics for appropriate application [6]. There are numerous studies in the cardiovascular literature that have employed TEE in swine models, but nearly all of these studies have dealt with cardiovascular physiology related to cardiac surgery [7], valvular abnormalities [8], myocardial infarction $[9,10]$, or cardiopulmonary resuscitation [11]. Data regarding the use of TEE in swine models is limited; one of the few papers describing the technique was published over 20 years ago [2], and baseline anatomical and hemodynamic parameters for TEE use in swine models have only recently been defined [1]. Both three-dimensional [8] and transthoracic ultrasound [12] in swine models have been described, but use of basic TEE in a swine model of hemorrhagic shock has not. Herein, we describe our experience using basic multiplane TEE to characterize hemodynamic changes in a large closed chest experimental swine model of non-compressible hemorrhage using resuscitative endovascular occlusion of the aorta (REBOA). The primary aim of this study is to describe an echocardiographic method that can be used with relative ease to qualitatively assess cardiovascular function in a porcine hemorrhagic shock model.

\section{Methods}

\section{Animal model}

The overall objective of this in vivo study was to characterize changes in arterial waveforms that occur during hemorrhage and uses Yorkshire swine (Sus scrofa) weighing between 70 and $90 \mathrm{~kg}$. Once animals were induced into hemorrhagic shock, animals were subsequently enrolled into various substudies which are reported separately. This study was study was undertaken at a certified laboratory, following Institutional Animal Care and Use Committee (IACUC) approval. The study consisted of two phases: animal preparation and volume controlled hemorrhage.

General anesthesia was induced using intramuscular ketamine (10-15 mg/kg) and xylazine (1-2.2 mg/kg) followed by intravenous propofol and ketamine and maintained with isoflurane (minimum alveolar concentration [MAC] range 1-4\%) by mask followed by tracheostomy intubation. Animals were ventilated using a volumecontrolled mode of $6 \mathrm{cc} / \mathrm{kg}$ with an $\mathrm{FiO} 2$ of $40-100 \%$ to maintain $\mathrm{SpO} 2>92 \%$. The jugular veins were cannulated bilaterally to permit intravenous access and placement of a Swan-Ganz catheter. An open cystostomy was performed for urine drainage.

Hemorrhagic shock was induced by removing $40 \%$ of the animal's blood volume over the course of $20 \mathrm{~min}$ from a femoral venous catheter. The first $20 \%$ of blood volume was removed over $7 \mathrm{~min}$, and the remaining 20\% of blood volume was removed over $13 \mathrm{~min}$.

In order to prevent hemorrhage induced cardiac arrest, animals were given fluid boluses with $500 \mathrm{~mL}$ of lactated ringers, if in the judgement of the anesthetist, the animal was deteriorating to the verge of cardiac arrest. The animals were euthanized at the end of the protocol. The study design is summarized in Fig. 1.

\section{Resuscitative endovascular balloon occlusion of the aorta (REBOA)}

Resuscitative Endovascular Balloon Occlusion of the Aorta (REBOA) is a hemorrhage control technique which allows for the attenuation of hemorrhage by temporarily occluding the aorta in order to support blood pressure until definitive hemostasis can be achieved [13, 14]. There has been considerable interest in performing REBOA closer to the point of injury and for prolonged durations 


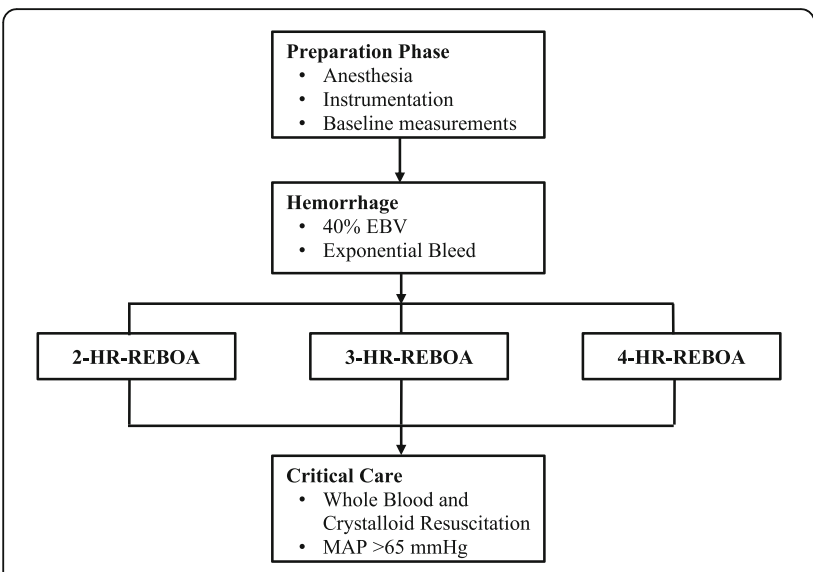

Fig. 1 Summary of the three experimental hemorrhage REBOA models. EBV-estimated blood volume. MAP-mean arterial pressure. REBOA-resuscitative endovascular balloon occlusion of the aorta. The time interval indicates the amount of time the REBOA balloon was inflated in zone I of the animal

in order to lessen the effects of extended transport time prolonged field care $[15,16]$. The physiologic effects of REBOA inflation for extended periods of time on the myocardium remains unknown. In this study, Zone 1 aortic occlusion was performed at the end of the hemorrhage protocol, with inflation of the balloon in the thoracic aorta (Fig. 2).

Aortic occlusion was confirmed using fluoroscopy.

\section{Multiplane TEE}

Both baseline and post-hemorrhage multiplane TEE was performed under general anesthesia using a General
Electrics LOGIQ $\mathrm{e}^{\circ}$ ultrasound machine with a 6Tc-RS TEE probe (General Electrics Healthcare, Chicago, IL). TEE exams were performed by anesthesiologists certified by the National Board of Echocardiography; one investigator was certified at the basic TEE level (SG) and another at the advanced level (BC). For multiplane TEE, four maneuvers were used: [1] mechanical rotation of the variable plane phased array between $0^{\circ}$ and $180^{\circ}$; [2] rotation of the shaft of the scope leftward and rightward; [3] advancement and withdrawal of the scope; and [4] tip anteflexion, retroflexion, and leftward and rightward flexion [2]. A basic TEE exam was performed using the 11 most relevant views recommended by the Consensus guidelines for basic perioperative TEE of the American Society of Echocardiography (ASE) and the Society of Cardiovascular Anesthesiologists (SCA) [6]. Specifically, the scope of practice for a basic TEE exam involves a limited application focused on intraoperative monitoring rather than specific diagnosis; a comprehensive exam, involving quantitative measurements is not within the scope of the basic perioperative TEE exam [6].

\section{Insertion of TEE probe}

The TEE probe was inserted as previously described by Ren et al. [2] A disposable transducer sheath $(100 \mathrm{~cm}$ long) was placed over the TEE probe with gel filling the inside and covering the tip of the probe. The distal portion of the probe was lubricated with gel and the probe was introduced while an assistant provided manual tongue elevation and retraction. With the swine in a supine position, the TEE scope was inserted blindly with the transducer array at $0^{\circ}$ rotation by directing the tip into the posterior part of the pharynx, gently allowing the

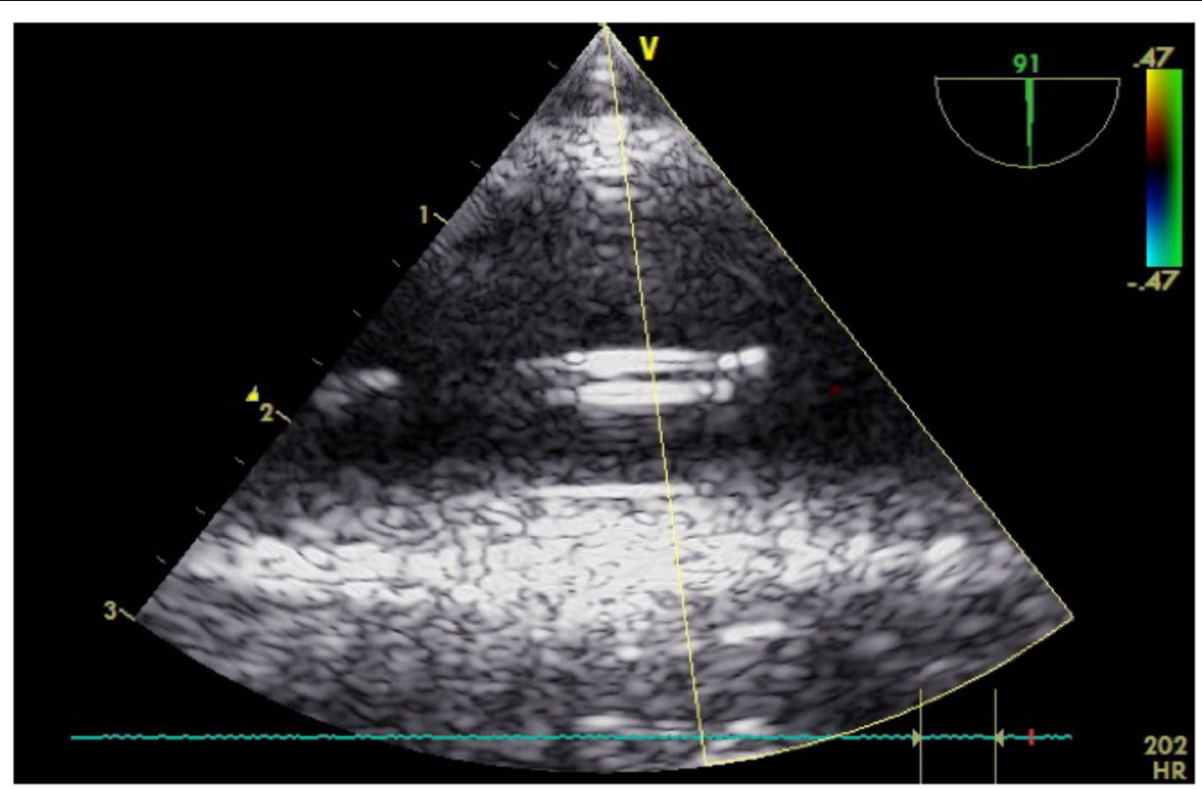

Fig. 2 Midesophageal descending aortic long axis view. The hyperechoic structure located in the middle of the plane is the REBOA catheter 
probe to flex passively, and advanced until images were obtained (approximately $45-60 \mathrm{~cm}$ from the incisors).

\section{Cardiac anatomical structure and function measurements} TEE images were recorded prior to experimental induction of bleeding and during occlusion with REBOA. The "iHeartScan ${ }^{\text {tum }}$ Form was used to record qualitative and quantitative data (University of Melbourne, AUS). The iHeartScan ${ }^{\mathrm{Tm}}$ is a limited echocardiography study that is qualitative and quantitative [17]. It is intended to be completed in approximately $10 \mathrm{~min}$ or $15 \mathrm{~min}$ for extended measurement. Components of the exam include qualitative assessments of ventricular volume in M-mode or $2 \mathrm{D}$, systolic function (including both the right and left ventricle), left atrial filling pressure (assessed by observing interatrial sepal motion), valve assessment, presence of pericardial effusion, and estimation of overall hemodynamic state (i.e., vasodilated, primary systolic or diastolic failure, right ventricular failure) [17]. Extended aspects of the iHeartScan $^{\mathrm{TM}}$ include calculation of ejection fraction, cardiac output, diastolic function (E/E, E/A ratios, etc.), and valve measurements. Advanced hemodynamic calculations were made for selected animals. Measurements of chambers and great vessel diameters were obtained as recommended by the ASE/SCA Consensus guidelines [6]. Ejection fraction (EF) was calculated when using the Teichholz method $[18,19]$. Stroke volume was calculated by multiplying the left ventricular outflow tract (LVOT) diameter $\mathrm{x}$ LVOT velocity time integral (VTI) $[\pi \text { (LVOT diameter } / 2)^{2} \mathrm{x}$ LVOT VTI]; cardiac output was calculated by multiplying stroke volume $\mathrm{x}$ heart rate.

\section{Statistical analysis}

Descriptive statistics were employed as appropriate according to the parametric or nonparametric nature of the data. Continuous data are described with a mean \pm standard deviation. A $P$ value of $<0.05$ was considered statistically significant. Data were analyzed using the $R$ package (version 3.1.1) for statistical computing ( $\mathrm{R}$ Foundation for Statistical Computing, Vienna, Austria).

\section{Results}

Basic TEE exams were performed in all 15 swine. The mean animal weight was $79.6 \pm 5.5 \mathrm{~kg}$. Heart rate significantly increased after REBOA inflation (76.8 [S.D. 21.3] vs. 151 [S.D. 47.1]; $p<0.001$ ) with a corresponding significant increase in shock index, but mean arterial blood pressure did not change significantly. Qualitative basic TEE findings are summarized in Table 2.

With the exception of mean pulmonary artery systolic pressure in the 2-h experimental groups, no significant changes were observed in pulmonary artery pressures despite echocardiographic findings indicating hypovolemic shock. Similarly, there were no statistically significant differences in mean arterial blood pressure in any of the three study arms prior to and after REBOA inflation, despite experimental blood loss of $40 \%$. In all animals, basic TEE qualitatively revealed increased LV function and hypovolemia as evidenced hyperdynamic physiology.

In a convenience sample (two animals from each group), advanced functional cardiovascular measurements were obtained before and after REBOA inflation for comparison with qualitative assessments. Mean ejection fraction (EF) decreased from 64\% (S.D. 9.6) to 62.1 (S.D. 16.8) after hemorrhage and REBOA inflation $(p=0.76)$; fractional area of change (FAC) decreased from 49.8 (S.D. 9.0) to 48.5 (S.D. 13.6) after hemorrhage and REBOA inflation $(p=0.82)$. VTI and LVOT measurements were obtained in animals; mean cardiac output was $3.7 \mathrm{~L} / \mathrm{min}$ prior to hemorrhage and REBOA inflation, and $7.6 \mathrm{~L} / \mathrm{min}$ thereafter.

Midesophageal aortic long and short axis views were obtained to confirm correct REBOA catheter position (Figs. 2, 3, and 4). Catheter position was verified in all animals with basic TEE and confirmed with the use of fluoroscopy.

\section{Discussion}

In a porcine closed chest experimental swine model of non-compressible hemorrhage using REBOA, use of basic multiplane TEE detected hemodynamic changes that could

Table 2 Summary of basic TEE findings and overall hemodynamic state during three experimental models ( $n=5$ animals in each phase)

\begin{tabular}{|c|c|c|c|c|c|c|c|c|c|}
\hline Model & Timing & $\begin{array}{l}\text { Shock } \\
\text { Index }\end{array}$ & $\begin{array}{l}\text { Pulmonary } \\
\text { Artery Pressure }\end{array}$ & $\begin{array}{l}\text { Mean } \\
\text { Arterial Pressure }\end{array}$ & $\begin{array}{l}\text { LV ventricular } \\
\text { volume }\end{array}$ & $\begin{array}{l}\text { RV ventricular } \\
\text { volume }\end{array}$ & $\begin{array}{l}\text { LV systolic } \\
\text { function }\end{array}$ & $\begin{array}{l}\text { RV systolic } \\
\text { function }\end{array}$ & Hemodynamic state \\
\hline \multirow[t]{2}{*}{$2 \mathrm{~h}$} & Pre-bleed & 0.63 & $37 / 27$ & 93.5 (13.6) & Normal & Normal & Normal & Normal & Normal \\
\hline & REBOA inflation & $1.24^{*}$ & $47^{*} / 26$ & $111.7(29.1)$ & Hypovolemic & Normal & Increased & Normal & Empty \\
\hline \multirow[t]{2}{*}{$3 \mathrm{~h}$} & Pre-bleed & 0.58 & $35 / 26$ & $115.3(13.2)$ & Normal & Normal & Normal & Normal & Normal \\
\hline & REBOA inflation & $0.96^{*}$ & $38 / 29$ & $114.3(14.8)$ & Hypovolemic & Normal & Increased & Normal & $\begin{array}{l}\text { Empty; mild } \\
\text { diastolic failure }\end{array}$ \\
\hline \multirow[t]{2}{*}{$4 \mathrm{~h}$} & Pre-bleed & 0.56 & $33 / 24$ & $116.6(31.2)$ & Normal & Normal & Normal & Normal & Normal \\
\hline & REBOA inflation & $0.91^{*}$ & $38 / 27$ & $100.3(20.6)$ & Hypovolemic & Normal & Increased & Normal & $\begin{array}{l}\text { Empty; mild } \\
\text { diastolic failure }\end{array}$ \\
\hline
\end{tabular}

Basic TEE exams were performed pre-bleed and post-bleed during REBOA inflation. Findings are summarized qualitatively for all animals; hemodynamic findings are described with means and standard deviation. Shock index $=$ heart rate / systolic blood pressure. ${ }^{*} P<0.01$ 


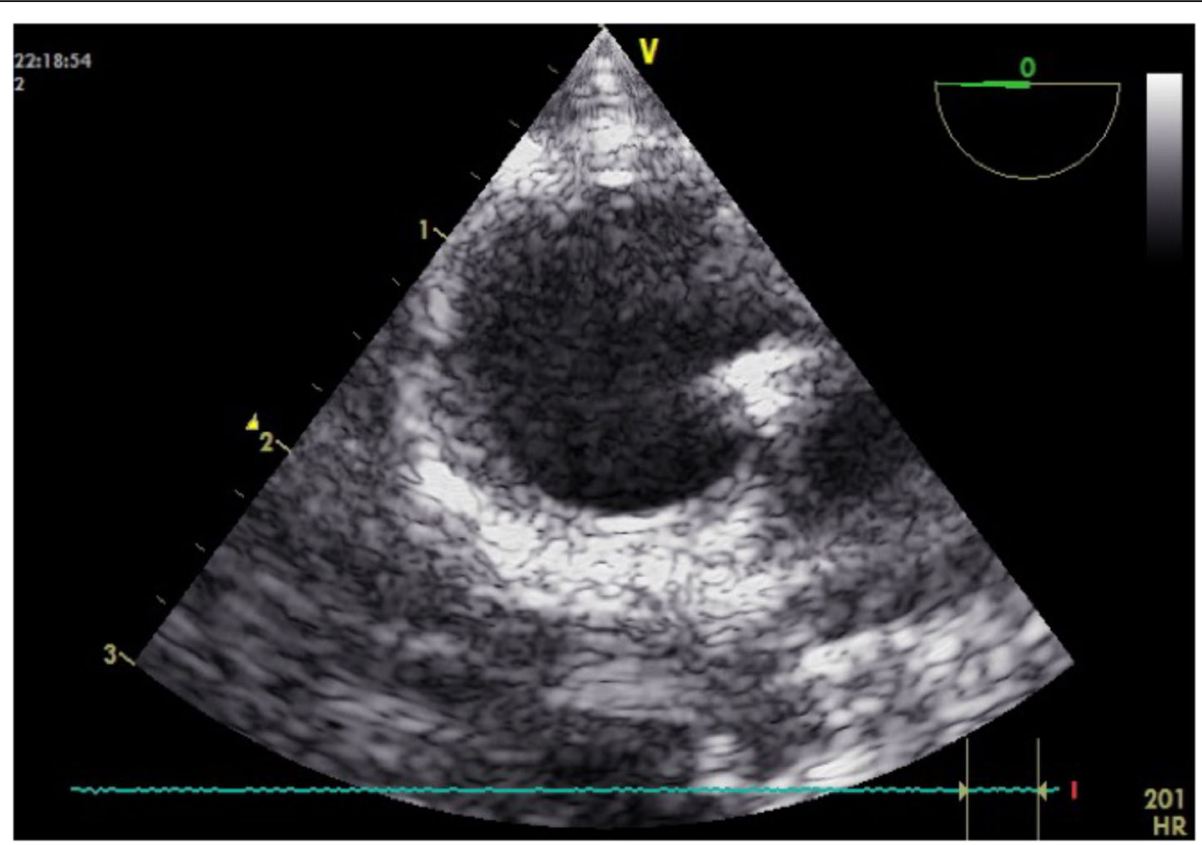

Fig. 3 Midesophageal descending aortic short axis view. The hyperechoic structure located in the right lower quadrant of the aorta is the REBOA catheter

not be verified with the use of mean arterial pressure and pulmonary artery catheter data. With the increasing use of REBOA in both experimental settings and clinical settings, methods to rapidly and accurately assess hemodynamics are required. The use of basic TEE is of interest to laboratory investigators and clinicians for several reasons. First, the goal of basic TEE is intraoperative monitoring; while TEE is invasive, at the basic level, TEE can be used by a wide variety of scientists and clinicians to observe hemodynamic changes associated with aortic occlusion and hemorrhage. Second, basic TEE may reveal earlier evidence of hypovolemia despite relatively normal

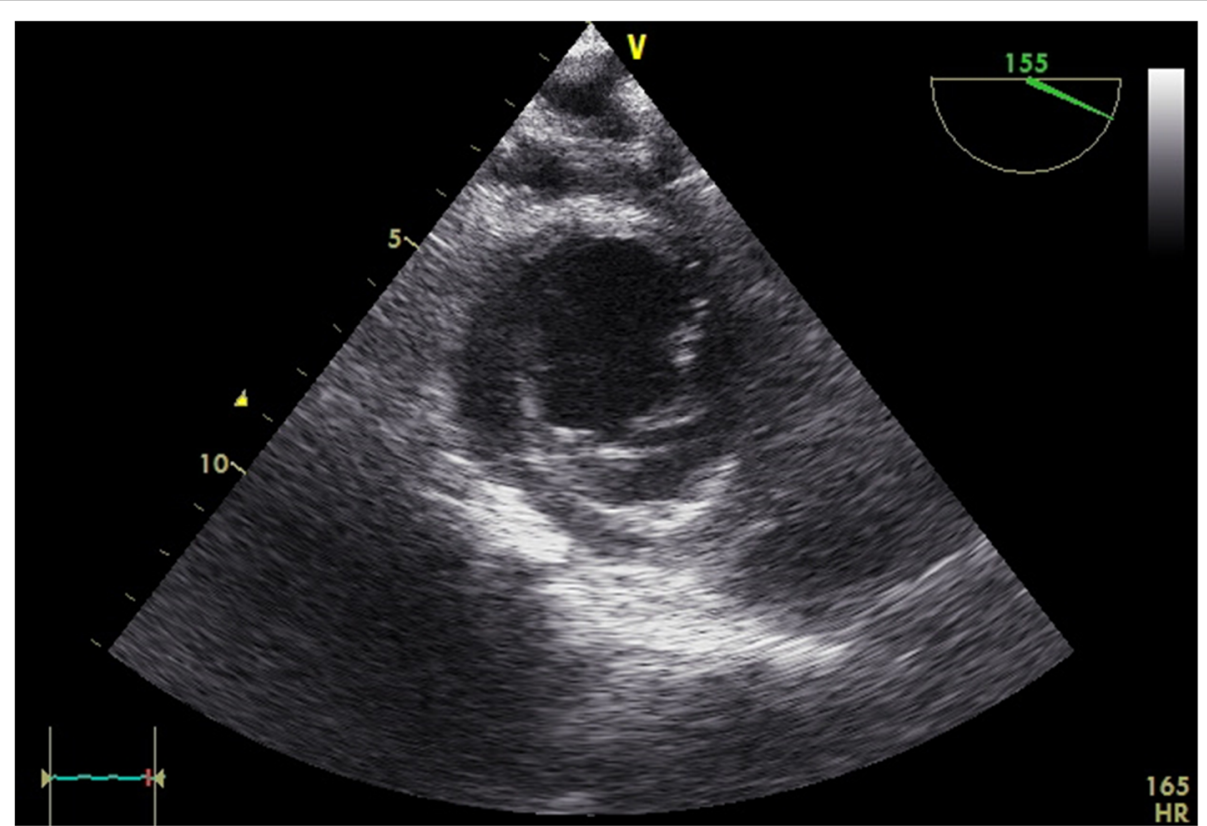

Fig. 4 A representative transgastric short axis transesophageal view. Such a view is useful for assessing early regional wall abnormalities indicative of myocardial dysfunction and overall volume status 
vital signs. Third, basic TEE may be helpful for localizing and confirming REBOA position. The primary goal of the basic TEE exam is intraoperative monitoring. The exam is not designed for practitioners to use the full diagnostic potential of TEE; hence, training requirements are considerably less than required for the advanced TEE exam [6]. Performance of basic TEE may be feasible in a wide variety of settings, including the laboratory, intensive care unit, and austere medical environments. Currently, "certification" is only available for licensed physicians who have passed an exam and demonstrated supervised performance of exams, but such requirements do not preclude performance of basic TEE exams in the laboratory by properly supervised investigators.

Limited application of TEE is potentially useful in both experimental and clinical settings where REBOA is employed for hemorrhage control because cardiac dysfunction is common in critical illness, but the effects on porcine and human hearts during REBOA are uncertain [20]. Basic TEE was feasible for all animals in our study. Clear evidence of hypovolemia was observed in all animals despite normal systemic and pulmonary blood pressure measurements. In animals with prolonged balloon inflation, evidence of early diastolic dysfunction was also observed, although in the subset of animals where $\mathrm{EF}$ and FAC were measured, no statistically significant differences were observed. These findings indicated a hyperdynamic cardiovascular state consistent with compensated shock. Such findings would be of great importance for both laboratory investigators and clinicians because further decreases in heart function would likely signify the upper limit of REBOA insertion before instituting definitive blood component resuscitation and surgical correction of hemorrhage.

An additional advantage of using basic TEE is for confirmation of proper REBOA location when fluoroscopic methods are not available. In previous studies, the subxiphoid view from a Focused Abdominal Sonogram for Trauma (FAST) was shown to reliably identify a central aortic guidewire, but in situations where the abdomen or chest is opened, such an exam may not be practicable [21]. In austere or limited resource settings when REBOA may be required as a temporizing measure for severe hemorrhage, fluoroscopy will likely be unavailable whereas a modern, compact TEE machine might be. In our study, a portable ultrasound machine weighing $11.5 \mathrm{lbs}$. $(5.2 \mathrm{~kg}$ ) was used. Moreover, use of TEE for both hemodynamic assessment and proper REBOA positioning obviates any exposure to radiation. In situations where REBOA has been employed for life-threatening hemorrhage, TEE has been used to confirm guidewire placement in the descending aorta [22]. Malpositioned REBOA, including inappropriate advancement into the ascending aorta, has potentially catastrophic consequences, including arrhythmia, carotid dissection, and coronary vasospasm [21]. Use of basic TEE is feasible with the advent of smaller, portable machines and probes, thus limiting radiation exposure and reducing the "footprint" associated with fluoroscopy.

There are several limitations to this work. Although the basic TEE exam requires less training and is easier to perform, advanced measurements, including functional measurement of stroke volume, cardiac output, stroke volume variation, and regional myocardial wall motion would likely be helpful to measure in future studies. Advanced calculations were obtained randomly in each experimental group for this study, but regular measurement of these parameters requires a more thorough exam performed by a practitioner with advanced TEE training. Basic TEE measurements were obtained prior to experimental hemorrhage and after REBOA inflation post-hemorrhage. Additional TEE exams conducted at regular intervals might have been more likely to reveal hemodynamic changes.

\section{Conclusions}

Basic TEE is feasible in porcine hemorrhagic shock models involving REBOA. This method can be performed with relative ease and may assist with early detection of hypovolemia and confirmation of precise proximal REBOA deployment. Basic TEE requires less training than advanced TEE and may be employed by laboratory investigators and practitioners across a wide spectrum of experimental and clinical settings.

\section{Abbreviations \\ ASE: American Society of Echocardiography; AUS: Australia; EF: Ejection fraction; FAC: Fractional area of change; FAST: Focused abdominal sonogram for trauma; IACUC: Institutional animal care and use committee; LVOT: Left ventricular outflow tract; MAC: minimal alveolar concentration; \\ REBOA: Resuscitative endovascular balloon occlusion of the aorta; \\ S.D.: Standard deviation; SCA: Society of Cardiovascular Anesthesiologists; TEE: Transesophageal echocardiography; VTI: Velocity time integral}

\section{Funding}

This study was supported by a grant (W81XWH-16-1-0116) from the Defense Medical Research and Development Program- Broad Agency, US Army Medical Research (Primary Investigator: Thomas Scalea, MD).

\section{Availability of data and materials}

All authors had access to the data and material availability throughout the study. Supporting data is available upon request from the primary (William Teeter) or senior (Samuel Galvagno) authors.

\section{Authors' contributions}

WAT, TMS, SMG, DP, MRH, and BG conceived and designed the study. WAT, PJW, JJM, BC, and SMG collected the data and performed the analysis. WAT, BC, and SMG drafted the manuscript. All authors critically reviewed the manuscript and data analysis. All authors read and approved the final manuscript.

\section{Ethics approval and consent to participate}

This study was study was undertaken at a certified laboratory, following Institutional Animal Care and Use Committee (IACUC) approval and the manuscript is compliant with the ARRIVE (Animal Research: Reporting of In Vivo Experiments) guidelines. 


\section{Consent for publication}

Data for this study was approved by release by the US Army Medical Research Directorate.

\section{Competing interests}

The authors declare that they have no competing interests.

\section{Publisher's Note}

Springer Nature remains neutral with regard to jurisdictional claims in published maps and institutional affiliations.

\section{Author details}

${ }^{1}$ University of North Carolina, Raleigh, North Carolina, USA. ${ }^{2}$ Department of Anesthesiology, Division of Trauma Anesthesiology, University of Maryland School of Medicine, Baltimore, MD, USA. ${ }^{3}$ Department of Surgery, University of Maryland School of Medicine, Baltimore, MD, USA. ${ }^{4}$ Department of Surgery, Program in Trauma, University of Maryland School of Medicine, Baltimore, MD, USA. ${ }^{5}$ Department of Surgery, Walter Reed National Medical Center, United States Army, Bethesda, MD, USA. ${ }^{6}$ Department of Surgery, Emory University, Atlanta, GA, USA. "University of Maryland, Program in Trauma, Baltimore, MD, USA. ${ }^{8}$ Department of Anesthesiology, Divisions of Critical Care Medicine and Trauma Anesthesiology, University of Maryland School of Medicine, Baltimore, MD, USA.

Received: 22 March 2018 Accepted: 25 June 2018

Published online: 16 July 2018

\section{References}

1. Huenges K, Pokorny S, Berndt RCJ, Lutter G. Transesophageal echocardiography in swine: establishment of a baseline. Ultrasound Med Biol. 2017:43:974-80.

2. Ren JFSD, Lighty GW Jr, Menz W, Michele JJ, Li KS, Dillon SM, Marchlinski FESB. Multiplane transesophageal and intracardiac echocardiography in large swine: imaging technique, normal values, and research applications. Echocardiography. 1997;14:135-48.

3. Morrison JJRJ, Rt H, Watson JD, Sokol KK, Rasmussen TE. Use of resuscitative endovascular balloon occlusion of the aorta in a highly lethal model of noncompressible torso hemorrhage. Shock. 2014;41:130-7.

4. Scott DJEJ, Villamaria C, Morrison JJ, Houston R 4th, Spencer JR, TE R. A novel fluoroscopy-free, resuscitative endovascular aortic balloon occlusion system in a model of hemorrhagic shock. J Trauma Acute Care Surg. 2013; 75:122-8.

5. Crick SJ, Sheppard MN, Ho SY, Gebstein L, Anderson RH. Anatomy of the pig heart: comparisons with normal human cardiac structure. J Anat. 1998; 193:105-19.

6. Reeves ST, Finley AC, Skubas NJ, et al. Basic perioperative transesophageal echocardiography examination: a consensus statement of the American Society of Echocardiography and the Society of Cardiovascular Anesthesiologists. J Am Soc Echocardiogr. 2013;26(5):443-56.

7. Bartel TMS, Caspari G, Erbel R. Intracardiac and intraluminal echocardiography: indications and standard approaches. Ultrasound Med Biol. 2002;28:997-1003.

8. Sündermann SHCN, Falk V, Bettex D. Two- and three-dimensional transoesophageal echocardiography in large swine used as model for transcatheter heart valve therapies: standard planes and values. Interact Cardiovasc Thorac Surg. 2016;22:580-6.

9. Ellenbroek GH vHG, Timmers L, Doevendans PA, Pasterkamp G, Hoefer IE. Primary outcome assessment in a pig model of acute myocardial infarction. J Vis Exp. 2016;(116):1-9.

10. Meybohm PGM, Renner J, Maracke M, Rossee S, Höcker J, Hagelstein SZK, Bein B. Assessment of left ventricular systolic function during acute myocardial ischemia: a comparison of transpulmonary thermodilution and transesophageal echocardiography. Minerva Anestesiol. 2011;77:132-41.

11. Anderson KLCM, Boudreau SM, Sharon DJ, Bebarta VS. Left ventricular compressions improve hemodynamics in a swine model of out-of-hospital cardiac arrest. Prehosp Emerg Care. 2017;21:272-80.

12. Kerut EKVC, Luka T, Pinkernell K, Delafontaine P, Alt EU. Technique and imaging for transthoracic echocardiography of the laboratory pig. Echocardiography. 2004;21:439-42.

13. Sridhar S, Gumbert SD, Stephens C, Moore L, Pivalizza EG. Resuscitative endovascular balloon occlusion of the aorta: principles, initial clinical experience, and considerations for the anesthesiologist. Anesth Analg. 2017; 125:884-90.

14. Russo RM, Williams TK, Grayson JK, et al. Extending the golden hour: partial resuscitative endovascular balloon occlusion of the aorta in a highly lethal swine liver injury model. J Trauma Acute Care Surg. 2016;80:372-8. discussion 8-80

15. Sadek S, Lockey DJ, Lendrum RA, Perkins Z, Price J, Davies GE. Resuscitative endovascular balloon occlusion of the aorta (REBOA) in the pre-hospital setting: an additional resuscitation option for uncontrolled catastrophic haemorrhage. Resuscitation. 2016;107:135-8

16. Manley JD, Mitchell BJ, DuBose JJ, Rasmussen TEA. Modern Case Series of Resuscitative Endovascular Balloon Occlusion of the Aorta (REBOA) in an Outof-Hospital, Combat casualty care setting. J Spec Oper Med. 2017;17:1-8.

17. iHeartScan. 2017. Retrieved on 26 June 2018 at www.HeartScan.com.

18. Teichholz LE, Kruelen T, Herman MV, Gorlin R. Problems in echocardiographic volume determinations: echocardiographic-angiographic correlations in teh presence of absence of asynergy. Am J Cardiol. 1976;37:7-11.

19. Arora G, Morss AM, Piazza G, et al. Differences in left ventricular ejection fraction using teichholz formula and volumetric methods by $\mathrm{cmr}$ : implications for patient stratification and selection of therapy. J Carrdiovasc Magn Reson. 2010;12:P202.

20. Orde S, Slama M, Hilton A, Yastrebov K, McLean A. Pearls and pitfalls in comprehensive critical care echocardiography. Crit Care. 2017;21:1-10.

21. Guliani S, Amendola M, Strife B, et al. Central aortic wire confirmation for emergent endovascular procedurs: as fast as surgeon-performed ultrasound. J Trauma Acute Care Surg. 2015;79:549-54.

22. Lai $\mathrm{CH}, \mathrm{Wu} \mathrm{HY}$. Resuscitation for an octogenarian with ruptured abdominal aortic aneurysm using endovascular balloon. Am J Emerg Med. 2008;26: 967e1-3.

\section{Ready to submit your research? Choose BMC and benefit from:}

- fast, convenient online submission

- thorough peer review by experienced researchers in your field

- rapid publication on acceptance

- support for research data, including large and complex data types

- gold Open Access which fosters wider collaboration and increased citations

- maximum visibility for your research: over $100 \mathrm{M}$ website views per year

At BMC, research is always in progress.

Learn more biomedcentral.com/submissions 